\title{
EL SOFTWARE SOCIAL Y LAS EMPRESAS DE FORMACIÓN. EL CASO DEL GRUPO MASTER-D
}

\section{THE SOCIAL SOFTWARE AND TRAINING COMPANIES. THE MASTER-D GROUP CASE STUDY}

Manuel Fandos Igado: Grupo Master-D

mfandos@masterd.es

Julio Tello Díaz: Universidad de Huelva (España)

jtellodiaz@eresmas.com

\section{CURRÍCULUM VITAE}

Asesor de Nuevas Tecnologías en el CEP de Ejea de los Caballeros de Zaragoza (España). Fue profesor asociado de la Universidad de Manchester (Gran Bretaña).

Licenciado y doctor en Psicopedagogía. Imparte docencia en la Universidad de Huelva (España) como profesor.

\section{RESUMEN}

Muchas son las estrategias de marketing que las empresas utilizan para dar a conocer sus productos y posicionar su imagen corporativa y de marca. En este sentido, hoy, la presencia en Internet es prácticamente obligatoria para cualquier empresa que se precie. El grupo Master-D, dedicado a la formación abierta y a distancia muestra cómo un uso adecuado y planificado de algunas de las 
posibilidades que ofrece la web 2.0, --basado en este caso en los blogs-, permite alcanzar mayores cotas de mercado y posicionamiento de marca sustentándose en el principio de «ganar - ganar». Los blogs, sin duda, son un canal que evidencia el poder de atracción que tiene una buena información.

\title{
PALABRAS CLAVE
}

Enseñanza Abierta - Web 2.0 - Empresas de Formación - Blogs - Internet - Marketing

\begin{abstract}
Companies use many different marketing strategies in order to make their products known and place their corporate image and branding in the market. Besides, nowadays, being on the Internet is a must for every company striving for success. A company devoted to open and distance learning such as Master-D Corporation is a clear example of how a proper and planned use of the different possibilities offered by the Web 2.0 -based on blogs- allows a company to achieve bigger market shares and brand positioning following the Win - Win Principle. Blogs are, undoubtedly, channels of communication that prove the power of attraction of good information.
\end{abstract}

\section{KEY WORDS}

Open Learning - Web 2.0 - Training Company - Blogs - Internet - Marketing

\section{ÍNDICE}

1. Introducción

2. La participación multidireccional 
3. Una decisión estratégica

4. En el horizonte

5. Referencias

\section{TEXTO}

\section{Introducción}

Hacemos nuestras las primeras palabras que abren el Estudio 2009 de la implantación y uso del software social en la empresa española 1 : «Han pasado ya ocho años desde que se diera un nombre Web 2.0 a un fenómeno que se presentaba como una revolución en la red. Sin embargo, en el ámbito empresarial aún no se está explotando todo el potencial que presentan estas herramientas», lo que no deja de ser una oportunidad que las empresas pueden estar dejando escapar.

Sin duda la Web 2 (y 3).0 (Aguaded y Fandos, 2008) está abriendo un conjunto de opciones en todos los ámbitos, también el educativo, que obliga a replantear muchos modelos y modos de actuación vigentes hasta hoy.

Estamos ante una revolución tecnológica que abunda y evidencia la «infoxicación» en la que estamos inmersos. Es evidente que vivimos tiempos de cambio, incluso contradictorios (Ortiz de Zárate, 2008) en los que la «invisibilidad» que genera el excedente de información puede ser contrarrestada, a su vez, por las posibilidades de participación altruista que ofrece el desarrollo de las tecnologías. 
En este sentido y aquí queremos destacar los blogs como elementos sobresalientes por su versatilidad, sencillez de creación 2, flexibilidad y posibilidades intercomunicativas.

Es conocido por todos que un blog es un sitio Web donde aparecen recopiladas ordenadas por fechas (primero la más reciente) las informaciones, mensajes, opiniones, reflexiones (posts) de los autores y sobre los que los lectores pueden escribir comentarios y los autores responderles, estableciendo de este modo, una interactividad o diálogo entre los usuarios.

En una primera instancia, por lo tanto, estamos con Lara (Lara, 2005) 3 -entre otrosen que la utilización de los blogs en la formación permite: fomentar una actitud crítica ante lo leído; aporta interactividad; facilita la audiencia de las distintas opiniones; permite la posibilidad de publicar; proporciona material de estudio; fomenta el debate, etc.

En definitiva, es un lugar privilegiado de trabajo cooperativo y es una potente herramienta social. Dos elementos especialmente relevantes en los procesos de enseñanza aprendizaje.

Es indiscutible que hoy el uso de las tecnologías en los ámbitos productivos y en el tejido empresarial es una realidad, creemos, además que en el ámbito educativo es algo ineludible; en esta sociedad de la información ya no cabe hablar de la apuesta por las tecnologías. Más aún, en nuestra opinión la empresa, sector productivo o colectivo que no tiene (y aplica) tecnologías o no existe o tiene sus días contados.

Pero qué tecnologías y para qué. Todas. Las que existen y las que existirán, porque para las empresas de formación las tecnologías no son más que el medio por el que 
poder llegar mejor y antes a dar un servicio excelente 4 (Aguaded y Fandos, 2008b). Más aún, las tecnologías las contemplamos hoy como un elemento imprescindible para hacernos visibles, un paso previo e imprescindible para poder llegar a dar el servicio que nuestros alumnos (clientes) nos demandan.

Es evidente, por lo tanto, que las empresas de hoy no tienen más opción que adaptarse a los cambios que estamos viviendo, en este caso, a aquellos que vienen de la mano de la Web 2.0. Al cabo, se trata tal vez, de una aproximación a lo que Andrew McAfee 5 denominó Enterprise 2.0 o lo que Julen Iturbe Ormaetxe 6 llamaba Empresas 2.0.

En el fondo se trata de aprovechar las posibilidades de la tecnología siendo conscientes de que este modo de actuar puede terminar proponiendo (de hecho lo hace) otros modelos y acaba generando un cambio en el sistema de valores de la organización. Cuestiones que no deben ser objeto de recelo, dado que el objetivo de la preparación de nuestros alumnos es la de capacitarlos para la integración en el mercado laboral que, cada vez más, se muestra más dinámico, más exigente y más abierto y para ello el camino que se dibuja pasa necesariamente por la adaptación de materiales y métodos docentes, la adaptación de horarios, de sistemas de atención, de modos de evaluación, etc. Y, por si fuera poco, para dar respuesta a todo este cúmulo de necesidades hemos de considerar también los nuevos modos de pensar y actuar (condicionados por las TIC) de los clientes - alumnos (y docentes).

1- http://www.fundacionorange.es/areas/25_publicaciones/softwaresocial2009.pdf [Fecha de consulta: 02/09/09] 
2- Escribiendo la sentencia «como crear un blog» en Google el buscador devuelve 672.000 entradas. [Fecha de consulta 02/09/09]

3-http:/ / www.campusred.net/telos/articulocuaderno.asp?idarticulo=2\&rev=65 [Fecha de consulta: 10/03/09]

4- En el caso del Grupo Master-D véase específicamente su misión en la siguiente dirección: $\quad$ http://www.grupomasterd.es/informacion-corporativa/misionprincipios-y-valores/ [Fecha de consulta 02/09/09]

5-http://sloanreview.mit.edu./themagazine/articles/2006/spring/47306/enterprise-the-dawn-of-emergentcollaboration/ [Fecha de consulta: 03/03/2009]

6-http:/ / blog.consultorartesano.com/2006/01/web-20-y-empresa-20-post-1continuara.html [Fecha de consulta: 03/03/2009]

\section{La participación multidireccional}

Cualquier empresa que se precie sabe que su supervivencia está condicionada a la adaptación a los tiempos y a las necesidades de sus clientes. Este «darwinismo empresarial» obliga a reflexionar sobre cuáles son las adaptaciones necesarias para garantizar la supervivencia de las compañías. Master-D no es una excepción en este sentido, al contrario, se debe posicionar en la vanguardia de estas adaptaciones por razón de su propia misión como empresa: «ayudar a que el mayor número posible de alumnos logre sus metas en el menor tiempo posible mediante un producto y un servicio excelentes» 7. 
Y si, como hemos avanzado, la digitalización y las redes están siendo el origen de un buen número de cambios tanto en los medios como en los modos de comunicación. En el modo de comunicación entre la empresa y el cliente (interno y externo) se impone cada día más una adaptación a esta situación.

Los nuevos medios permiten dirigirse y responder al cliente de forma mucho más personalizada. Esta situación provoca, entre otras cuestiones, que el acento se deba poner más en los contenidos, en la información que en canal que empleemos para llegar al cliente. La información ya no está condicionada por la periodicidad de los medios; hoy la actualización puede ser permanente, en tiempo real.

Hoy las empresas somos cada vez más conscientes de que el modelo de difusión de información, de creación de marca, de captación de clientes está superando el paradigma «punto - multipunto» (que, además es unidireccional).

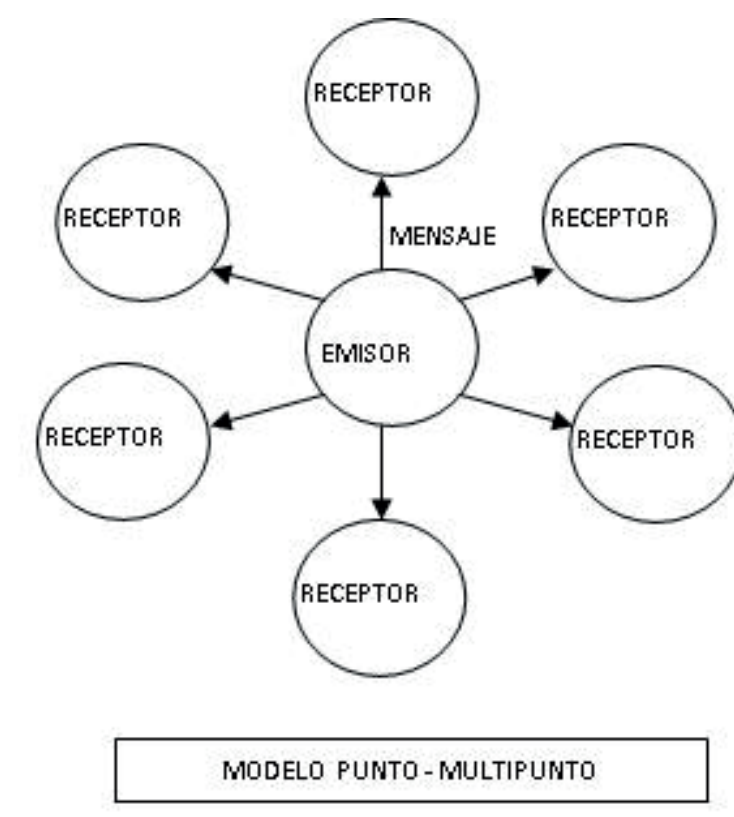

Paulatinamente, se va imponiendo el modelo «multipunto - multipunto» y, además multidireccional. 


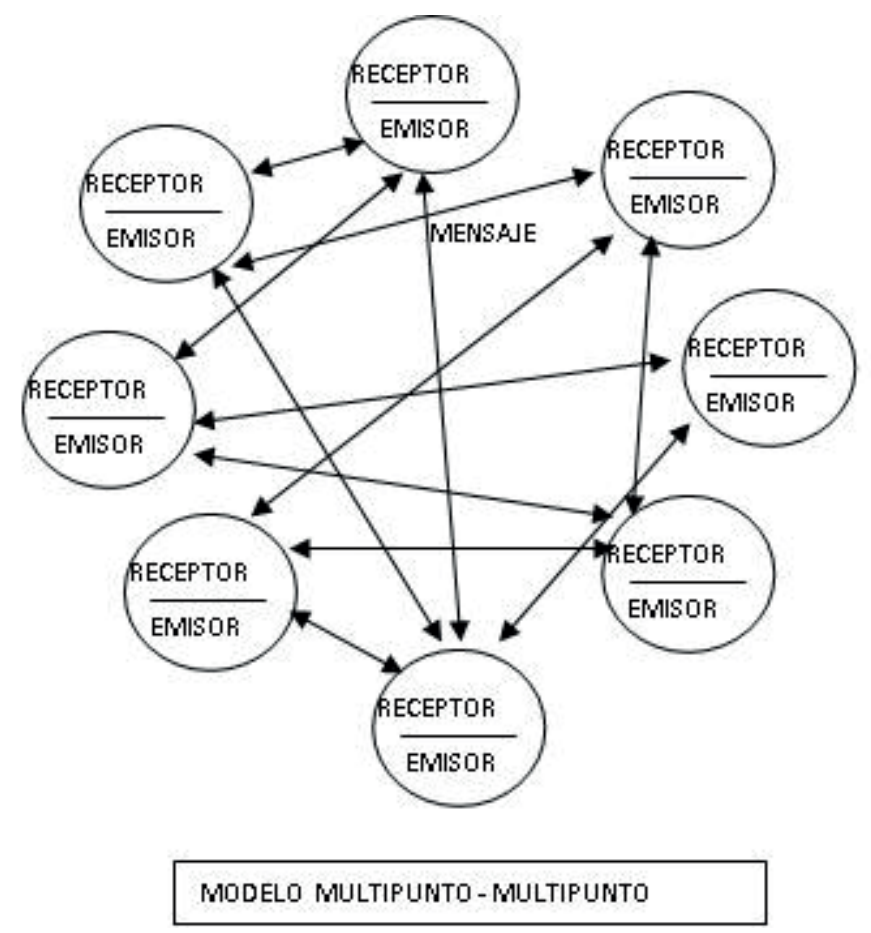

Es el usuario el que accede a los servidores donde está la información que busca o desea y además, es el propio usuario el que la amplifica dando pie a lo que algunos autores denominan el marketing viral 8

«El marketing viral y la publicidad viral son términos empleados para referirse a las técnicas de marketing que intentan explotar redes sociales preexistentes para producir incrementos exponenciales en conocimiento de marca, mediante procesos de autorreplicación viral análogos a la expansión de un virus informático. Se suele basar en el boca a boca mediante medios electrónicos; usa el efecto de red social creado por Internet y los modernos servicios de telefonía móvil para llegar a una gran cantidad de personas rápidamente».

Una cuestión que no es menor para las empresas de formación es que estas tienen como primer objetivo no solo conseguir clientes, sino fidelizarlos. Tenemos que considerar que las empresas de formación no tenemos «clientes cautivos» como es el 
caso de otras instituciones educativas y, como decíamos arriba, su primer objetivo es la supervivencia.

Volvamos sobre nuestros pasos. Las actuaciones tendentes a difundir información y captación de clientes consiguen, en una primera instancia, dos objetivos importantes: la creación de marca y elaboración de conocimiento. El mero hecho de estar en condiciones de hablar de algo, de ofrecer algo a los potenciales interesados, obliga a las compañías a estar actualizadas permanentemente en esos conocimientos.

Cabe decir, por lo tanto, que en este contexto que el usuario/cliente es el «rey». En el momento presente las empresas hemos de ser conscientes de que el modo de captación de clientes ha de ser a través de un modelo "centrado en el usuario» (Aguaded, I. y Fandos, M., 2008) buscando no solo el feedback sino, en lo posible, la interactividad.

De manera telegráfica y como resumen esencial de cuanto venimos diciendo: el interés que despierta la Web social (personalizado en este caso en los blogs) en el mundo empresarial crece cada día, fundamentalmente por estas dos razones fundamentalmente: permite la aproximación entre el cliente (real o potencial) y la empresa (es, por lo tanto, una clara herramienta de marketing relacional) y permite crear una red de conocimientos mutuos (en las dos direcciones) permitiendo la generación de confianza mutua.

Existen otras muchas razones que justificarían la apuesta empresarial por la Web social: difusión y consolidación de la cultura de empresa, creación de equipos de trabajo, desarrollo de proyectos, «networking», etc. 
7- Véase nota 4

8- http:/ / es.wikipedia.org/wiki/Marketing_viral [Fecha de consulta: 03/03/2009]

\section{Una decisión estratégica}

Master-D S.A. es un grupo internacional (radicado en España) cuyo cometido queda definido como sigue: «asesoramos, preparamos y entrenamos a las personas para que triunfen en el logro de sus metas profesionales y personales» 9. Así pues el objeto que define a esta compañía es la formación, la preparación y el entrenamiento.

Tres están siendo los ejes sobre los que están pivotando sus actuaciones en este sentido.

Por un lado el desarrollo e implementación de un modelo de formación abierta (Aguaded, I. y Fandos, M., 2008b) que en el momento presente le permite tener un volumen de unos 30.000 alumnos nuevos cada año (en los últimos cinco).

Por otro lado, el desarrollo específico de un modelo estructural y de participación que la propia compañía define como «empresa de empresarios» 10

Finalmente, el desarrollo de una serie de actuaciones tecnológicas tendentes a generar una «visibilidad», en este caso en Internet, que le permita a la compañía que se conozca tanto su marca como sus productos y servicios como la captación de clientes potenciales. Este conjunto de actuaciones están recogidas en su propio plan estratégico (PEC 2005-2014) 11. 
En el caso que nos ocupa, desde hace dos años ha venido implementando una serie de weblogs de manera paulatina, al tiempo que ha ido estableciendo mecanismos de control y seguimiento (todavía muy sencillos y en fase de revisión permanente) que le permiten ir comprobando el grado de aceptación e implicaciones derivadas del mismo de los distintos weblogs que poco a poco ha ido volcando en la Red.

Desde mediados de junio de 2007 en el que el grupo Master-D irrumpió con su estrategia de blogs en la Red, creando el «blog del opositor» (http:/ / blog.opositor.com) hasta el último de los blogs que la compañía ha puesto en funcionamiento (http:/ / www.masterdlabs.es), un blog profesional sobre tecnologías de la información y la comunicación a finales de 2008 han transcurrido 18 meses en los cuales, paulatinamente, han ido viendo la luz 3 blogs corporativos (específicamente diseñados y con objetivo de comunicar la esencia y actividad de la compañía en sus distintas sedes internacionales: -http://blogmasterd.es; http:// blogmasterd.gr; http://blogmasterd.pt-) y 4 blogs de temática específica: los dos ya citados $y$ un blog sobre energías renovables: http://www.blogenergiasrenovables.com y otro dedicado a la reflexión sobre el uso de las TIC (Tecnologías de la Información y la Comunicación) en la educación y en la enseñanza abierta y a distancia: http://www.masterdopina.es. 
Cuadro resumen. Fechas de creación de los blogs

\begin{tabular}{|c|c|}
\hline URL del blog & Fecha de creación \\
\hline http:/hlog.opositor.com & $25,06 / 2007$ \\
\hline hittp:/fwwowblogmasterd.es & $1203 / 2007$ \\
\hline hitp:/folog.masterd.pt & $22 / 10 / 2007$ \\
\hline http:Mblog.masterd.gr & $22 / 10 / 2007$ \\
\hline http://wwwb logene rgiasrenowables com & 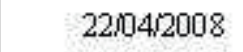 \\
\hline http:/hwww.masterdopina.es & $18,08 / 2008$ \\
\hline http:lihwww:masterdlabs.es! & $07 / 11 / 2008$ \\
\hline
\end{tabular}

Por su reciente creación todavía no hay datos concluyentes, sin embargo, sí que tenemos una primera conclusión derivada de la experiencia vivida hasta el momento: queremos seguir profundizando en esta línea de implementar, volcar en la red y mantener vivos alimentándolos con información estos y otros blogs que ahora mismo tenemos en estudio.

Somos conscientes de las importantes potencialidades que tienen los blogs para la enseñanza y, por ende para las compañías dedicadas a la formación (Villanueva, J.; Aced, C.; y Armelini, G., 2007) 12. Hacíamos referencia a alguna de estas cuestiones en el apartado anterior de este relato. No obstante, este caso, y por el momento, solo estamos incidiendo en la dimensión externa de los blogs, porque entendemos que las evidentes ventajas que la Web social ofrece a las empresas de formación para llevar a cabo su función solo se pueden dar en el caso de que tenga clientes (alumnos) y por lo tanto ahora entendemos que es una cuestión de mayor prioridad el comprobar hasta qué punto el uso de estas herramientas (blogs) permiten a la compañía el objetivo de captar un mayor número de potenciales clientes. 
En una primera fase de nuestro análisis hemos observado que existe una correlación entre las visitas a nuestros distintos blogs con el tráfico generado en nuestra página (www.masterd.es); del mismo modo, tenemos contrastado que un porcentaje de ese tráfico que llega a nuestra Web termina solicitando algún tipo de información y un porcentaje de éstos terminan siendo clientes de la compañía, de tal modo que la presencia de los weblogs, en una primera instancia está consiguiendo que tengamos más clientes, y por tanto mayor oportunidad de negocio.

Una muestra del alcance de los resultados:

Comparamos los segundos semestres de los años, por ser el momento en el que nacen y se ponen en funcionamiento los blogs y para evitar, en lo posible, variables como la estacionalidad, pretendiendo que existe alguna razón o variable no contemplada afecte del mismo modo en los distintos periodos controlados.

\begin{tabular}{|c|ll}
\hline Periodo de tiempo & Visitas a bs blogs & \multicolumn{1}{c}{ Visitas a h web } \\
\hline Julio - Dicie mbre 2006 & 0 & 637.548 \\
\hline Julio - Dicie mbre 2007 & 14.611 & 893.676 \\
\hline Julio - Dicie mbre 2008 & 60.645 & 1.192 .616 \\
\hline
\end{tabular}

La situación a día de hoy:

\begin{tabular}{|r|ll}
\hline Periodo de tiemp 0 & \multicolumn{1}{|l|}{ Visitas a bs blogs } & \multicolumn{1}{c|}{ Visitas a h web } \\
\hline Enero-Agosto 2008 & 70.965 & 1.362 .304 \\
\hline Enero-Agosto 2009 & 171.380 & 2.036012 \\
\hline
\end{tabular}

Somos conscientes de que esta variación en el tráfico de nuestra Web no es achacable únicamente a la existencia de los blogs. Son muchos los factores que inciden en este hecho del aumento de las visitas. El tráfico por la red ha crecido de manera sustancial 
en los últimos años por muchas razones, no es el momento de atender a esta cuestión. La actualización permanente de la información que se ofrece en la Web, sin duda es un elemento sustancial que afecta al volumen de visitas, los enlaces a otras Webs, cambios en los diseños, la referenciación de otras páginas, etc. Está claro que son muchos los factores que influyen. En todo caso, no es el momento de atenderlos aquí ahora.

Precisamente para poder determinar qué tráfico viene generado o derivado desde los distintos blogs hicimos una prueba a título testimonial, colocando en el blogmasterd.es y en distintos momentos un «piloto» que nos permitiera conocer mejor la trazabilidad (monitoreo) del origen de la visita $\mathrm{y}$, sin duda, cabe decir, después de esta experiencia, que el tráfico en los blogs correlaciona positivamente con el tráfico en la Web de la compañía que pretende captar clientes.

Obviamente, el tráfico que soportan los distintos weblogs depende de los «posts» que albergan y de los «tags» utilizados en los mismos.

De entre las muchas tareas que quedan pendientes, mejorar estas cuestiones y conseguir una sindicación (RSS) mejor se perfilan, en este sentido, como tareas prioritarias.

En el momento presente tenemos distintos pilotos en el «blog del opositor» que señalan en la misma dirección que las primeras conclusiones.

Por otra parte, y a pesar de que los resultados, en una primera instancia parecen indicar que este es uno de los caminos que merece la pena explorar, existen algunas consideraciones que hay que contemplar y que afectan directamente a las decisiones estratégicas de las empresas, por eso el epígrafe que reflejamos para este apartado. 
Los dos que queremos evidenciar aquí y ahora son:

a) el desarrollo de estas herramientas que permiten un mayor nivel de participación tiene que venir acompañado de una cierta «democratización» de la organización;

b) hay que estar dispuesto a perder el control del mensaje corporativo 13. Una vez lanzado a la red, es de los Internautas, por eso (Carreras, 2008) hay que ser consciente, y apostar por que «la verdadera influencia está en la verdad y hoy más que nunca es necesario construir relaciones con los públicos basadas realmente en la verdad y el tono personal, en la honestidad y la comunicación bidireccional y en el auténtico «feedback».

En clave empresarial hay alguna dificultad más, tal vez la más evidente es la dificultad que aún tenemos hoy para evaluar de forma fiable la incidencia de este tipo de trabajo en la productividad de los empleados, es un tema más de entre los que dejamos para posteriores oportunidades.

9- Véase nota 4

10 Véase el modelo estructural del Grupo Master-D: http://www.grupomasterd.es/el-por-que-de-nuestro-exito/modelo-estructural/ [Fecha de consulta: 02/09/09]

11 http://www.grupomasterd.es/informacion-corporativa/plan-estrategico/ [Fecha de consulta: 02/09/09] 
12- http://www.divshare.com/download/launch/1420234-e2f [Fecha de consulta: 04/03/2009]

13-http:/ / robertocarreras.es/ post/ 66210068/y-si-pierdo-el-control-del-mensajecorporativo [Fecha de consulta: 02/09/09]

\section{En el horizonte}

Siguiendo la referencia que hacíamos arriba sobre el «darwinismo empresarial», es evidente que la adaptación de la empresa al futuro inmediato pasa necesariamente por una revisión del uso y posibilidades que las TIC ofrecen, entre otros aspectos, como facilitadoras de una «visibilidad necesaria» en esta época de «infoxicación».

Para ello, hay que contemplar un paradigma de trabajo en el que el «ser participante» sustituya al «ser observado»; en el que, además, los directivos de las empresas hemos de estar presentes (hacernos visibles) en la Red, para responder a quienes nos lo demanden, para generar confianza en la marca, el producto y el servicio que ofrecen nuestras compañías. Al final se trata de crear notoriedad, generar credibilidad, tener la habilidad para «dirigir» la conversación y comprometerse unos con los otros.

Estamos con Carreras (2009) en que quizá en unos años hablemos de los «Social Media Management» o «Responsabilidad en Medios Sociales» con la misma familiaridad con la que hoy hablamos de Liderazgo, Management o RSC. Mientras tanto, habremos de contentarnos con intentar estar en este caso, por la mediación de los blogs, donde el consumidor está creando contenido, modelando la marca y hablando de ella y descubriendo ideas potencialmente interesantes para nuestras compañías. 
Con cautela todavía, pero con la certidumbre de que esta línea de trabajo nos está brindando resultados satisfactorios cabe decir que los blogs corporativos permiten ventajas competitivas contrastables en las empresas.

Es evidente que los blogs son una potente herramienta de comunicación corporativa que facilita la interactividad con un público que potencialmente puede convertirse en cliente de la compañía que auspicia el blog y que, sin duda ninguna, como primer resultado mejora el posicionamiento de la web de la empresa que pretende la captación de clientes en los buscadores.

En todo caso es una herramienta que debe estar claramente alineada con el plan estratégico y de comunicación de la firma y ha de estar perfectamente sintonizado con la cultura de la empresa.

Permite, además, contar con una fuente importante de información de la opinión de los usuarios (clientes potenciales) e incluso de los trabajos o líneas de desarrollo de otras empresas del sector o de la competencia.

Por lo tanto, cabe decir que esta opción (y sus riesgos correspondientes) conlleva «visibilidad» de la empresa, como decíamos, por el mejor posicionamiento en los buscadores de Internet; genera comunidad «networking» entre otros blogs (y sus correspondientes bloguers) en primera instancia, e incluso de los propios directivos que alimentan los blogs temáticos por poder llegar a ser considerados como una autoridad y referente en esa área del saber; permite un «feedback» inmediato y obliga a actualizar (y crear difundiendo) conocimientos específicos, lo que permite en las empresas la «potenciación del talento» de algunos de sus empleados. 
Desde el punto de vista publicitario «stricto sensu» la empresa, a través de sus blogs, se convierte en su propia valla publicitaria, que, llevado al extremo, puede incluso ser generadora de tendencias.

En todo caso, también hay que señalar que si la empresa no es transparente, si no tiene la máxima disposición para dar toda la información que se le demande e incluso aceptar unas críticas razonadas y razonables, la Web social, y desde luego lo blogs, no deben ser sus herramientas. Al final, se trata de ser lo más «auténtico» posible.

Después de tomada esta decisión estratégica, hoy por hoy parece claro que para buscar clientes debemos crear una comunidad, crear grupos y foros de debate (y por lo tanto dedicar un tiempo importante a esta tarea) hasta el punto de que las empresas deberían valorar la figura del «Comunity Manager» que se encargue de canalizar estos mensajes e informaciones que hay en la Red sobre las compañías, para plantear acciones que permitan adaptar la marca a las auténticas necesidades de sus clientes.

\section{Referencias}

AGUADED, I.; FANDOS, M. (2008) «Web 2 (y 3).0 desde una óptica empresarial» [artículo en línea]. EDUTEC, Revista Electrónica de Tecnología Educativa. Núm. 26/Julio 2008. [Fecha de consulta: 04/03/2009]. http://edutec.rediris.es/revelec2/revelec26/

AGUADED, I.; FANDOS, M. (2008b) «Blended Learning: The Key to Success in a Training Company» [artículo en línea]. ITDL. Intenational Journal of Instructional Technology and Distance Learning, Vol 5. Num. 8. [Fecha de consulta: 26/11/2008]. 
CARRERAS, R. (2008): ¿Y si pierdo el control del menaje corporativo? Blog de Roberto Carreras. Documento en línea: http://robertocarreras.es/post/66210068/ysi-pierdo-el-control-del-mensaje-corporativo [Fecha de consulta: 02/09/09]

CARRERAS, R. (2009): La clave de la participación corporativa en los Social Media. Blog de Roberto Carreras. Documento en línea: http:// robertocarreras.es/ post/81490791/la-clave-de-la-participaci-n-corporativaen-los-social [Fecha de consulta: 02/09/09].

LARA, T. (2005) «Blogs para educar. Usos de los blogs en una pedagogía constructivista». Telos. http:/ / www.campusred.net/telos/articulocuaderno.asp?idarticulo=2\&rev=65 [Fecha de consulta: 10/03/09]

FUNDACIÓN ORANGE - TIGE (2009): Estudio 2009 de la implantación y uso del software social en la empresa española. http://www.fundacionorange.es/areas/25_publicaciones/softwaresocial2009.pdf [Fecha de consulta 02/09/09]

ORTIZ DE ZÁRATE TERCERO, A. (2008): Manual de uso del blog en la empresa. Cómo prosperar en la sociedad de la conversación. Zero Factory S.L. Barcelona.

MASTER-D, (2005): Plan estratégico 2005-2014. El 2014 empieza hoy. Documento en línea: http://www.grupomasterd.es/pdfs/pec/CAT_PEC(01).pdf [Fecha de consulta: 02/09/09] 
VILLANUEVA, J.; ACED, C. y ARMELINI, G. (2007): Los blogs corporativos: una opción, no una obligación. E-busines Center ProcewaterhouseCoopers \& IESE. Madrid 